\title{
Hot water epilepsy: A form of reflex epilepsy - from infancy to adolescence
}

\author{
Rajath Pejaver, V. Srinivasa, S. P. Basavanthappa, C. L. Srinivasa Murthy \\ Department of Pediatrics, Basaveshwara Medical College Hospital and Research Centre, Chitradurga, Karnataka, India
}

\section{ABSTRACT}

Hot water epilepsy (HWE) is a type of reflex epilepsy which occurs when hot water is poured over the head. Most cases have been reported from Southern India. Genetic, cultural, and geographical factors can be responsible for HWE. HWE can be treated by clobazam 1-2 h prior to take a bath rather than continuous anti-epileptic therapy. Medication prior to bathing may be useful in treating older children, eliminating the need to be accompanied by an adult during bathing. It can also be treated by reducing the temperature of the water used for bathing. Here, we report three cases of HWE in varying age groups.

Key words: Epilepsy, hot water, intermittent clobazam prophylaxis, reflex seizures

\section{Introduction}

Epilepsy precipitated by the stimulus of bathing with hot water poured over the head is known as hot water epilepsy (HWE). ${ }^{[1-7]}$ These were also known as water-immersion epilepsy ${ }^{[8]}$ or bathing epilepsy. ${ }^{[9-11]}$ HWE is a term used to encompass a reflex epileptic condition, characterized by pouring hot water $\left(40-50^{\circ} \mathrm{C}\right)$ on the head. ${ }^{[3]}$ although it has been reported from all parts of the world, it is more prevalent in the Southern Indian population as most of the reported cases have been from there. ${ }^{[4]}$ It has been rarely reported in other European countries, and isolated case reports have been published from Japan and Turkey. ${ }^{[5]}$

Geographically, specific epilepsy syndromes are of epidemiologic interest and may assist in understanding the pathogenic mechanism of epilepsy in general. It may have a genetic basis with added environmental influence.

\section{Address for correspondence:}

Dr. Rajath Pejaver, Department of Pediatrics, Basaveshwara Medical College Hospital and Research Centre, NH 4, Near Housing Board Colony, Chitradurga - 577 501, Karnataka, India.

E-mail: rajath.pejaver@gmail.com

\begin{tabular}{|l|l|}
\hline \multicolumn{2}{|c|}{ Access this article online } \\
\hline Quick Response Code: & Website: \\
\hline & www.ruralneuropractice.com \\
\hline & \\
\hline
\end{tabular}

Here, we report three cases of HWE from India.

\section{Case Reports}

\section{Case 1}

A 15-year-old girl child from Chitradurga district in the state of Karnataka-India had presented to the emergency ward with a history of generalized seizures. Mother noticed that after pouring hot water on the head, while giving the bath, the child suddenly became floppy and developed generalized seizures with the loss of consciousness. She has had similar episodes from the age of 5 years. Each episode is preceded by pouring hot water over head while taking a bath and splashing water on her body never caused seizures. She had been started on several anticonvulsants by several doctors, but they had been discontinued as they had been ineffective in preventing seizures. The details of previous treatment were unfortunately unavailable. We were also unsure about her compliance with previous treatment. Her birth was uneventful, and the development was normal. There was no family history of similar seizures. On examination, the child was afebrile, conscious, and there were no

This is an open access article distributed under the terms of the Creative Commons Attribution-NonCommercial-ShareAlike 3.0 License, which allows others to remix, tweak, and build upon the work non-commercially, as long as the author is credited and the new creations are licensed under the identical terms.

For reprints contact: reprints@medknow.com

How to cite this article: Pejaver R, Srinivasa V, Basavanthappa SP, Murthy CS. Hot water epilepsy: A form of reflex epilepsy - from infancy to adolescence. J Neurosci Rural Pract 2015;6:607-9. 
neurological deficits. Routine blood tests, including complete blood count, serum electrolytes, serum calcium, blood sugar, and magnetic resonance imaging (MRI) brain, as well as electroencephalography (EEG) were within normal limits. The seizure was provoked in the hospital under controlled settings, and the child developed generalized tonic-clonic seizures within $30 \mathrm{~s}$ of pouring water on her head which was heated to $42^{\circ} \mathrm{C}$. The seizure was controlled with intravenous midazolam. Treatment with anti-epileptic drugs (AEDs) was planned to prevent HWE in this child. The main reason to try this treatment was the advanced age of the child and enables her to be more independent. Phenytoin (PHT) and carbamezepine were two options, but both require to be taken daily. Hence intermittent prophylaxis with clobazam (CLB) to be taken $2 \mathrm{~h}$ prior to having a head bath was considered. The next day, the child was given $5 \mathrm{mg}$ of CLB and seizure provocation was attempted after $2 \mathrm{~h}$. EEG could not be recorded during the attempted seizure provocation. The child did not have a seizure after pretreatment with CLB. The child was discharged with instructions to take CLB $2 \mathrm{~h}$ before having a bath. They were also advised to reduce the temperature of the water while bathing. In the follow-up visits, the parents reported that the child did not have any seizure recurrences.

\section{Case 2}

A one and half-year-old male child from Chitradurga district of Karnataka-India presented to the emergency ward with a history of seizures. Mother noticed that after pouring hot water on the head, while bathing the child, he suddenly had up rolling of the eyes with stiffening of all four limbs followed by jerky movements of both upper and lower limbs, lasting approximately $2 \mathrm{~min}$. His birth was uneventful, and the development was normal. On examination, the child was afebrile, conscious, and there were no neurological deficits. Routine blood tests, including complete blood count, electrolytes and neuroimaging (MRI brain) as well as EEG were within normal limits. Diagnosis of HWE was made, and the parents were counseled regarding its benign course and no anti-epileptic medications were prescribed considering the young age of the patient. Parents were advised to reduce the temperature of the water to tolerably lower levels while bathing the child. In the follow-up visits, the mother reported that there was one episode of minor motor fit when the child was bathed using hot water by the grandmother.

\section{Case 3}

A3-month-old male child was brought to the emergency ward with a history of seizures soon after pouring the hot water over the head while bathing the child. The child developed stiffening of all four limbs followed by jerky movements of all limbs, lasting approximately 2-3 min. Mother gave a history of similar episode 1-week ago which also occurred soon after pouring hot water over the child's head. Mother gives a family history of similar seizures in her sister's child, following hot water bath. On examination, the child was afebrile, conscious, and playful. Routine blood tests, including complete blood count, electrolytes, and serum calcium were normal. MRI brain as well as EEG, were within normal limits. Cerebrospinal fluid analysis was normal. Diagnosis of HWE was made, and the parents were counseled regarding its benign course and no anti-epileptic medications were prescribed. Parents were advised to reduce the temperature of the water to tolerably lower levels while giving a bath to this child. In the follow-up visits, the mother did not report any recurrences of seizures.

\section{Discussion}

Reflex epilepsy is a condition in which the seizures are provoked exclusively by an external stimulus and account for $6 \%$ of all epilepsies. ${ }^{[6]}$ HWE is a form of reflex epilepsy, precipitated always, by bathing in hot water. Thus, this mode of reflex epilepsy requires a specific thermal cutaneous stimulus. Both partial and generalized tonic seizures have been described secondary to hot water bathing, however, one third of all reported cases have primary generalized tonic-clonic seizures. ${ }^{[6,9,10]}$ The highest incidence of HWE is in Yelandur, a rural area near Mysore in Karnataka-India and quoted a prevalence rate of 255/100,000 for HWE. Interictal scalp EEG is usually normal, but $15-20 \%$ might show diffuse abnormalities. ${ }^{[4,6,7]}$ The exact mechanism of HWE remains uncertain, but altered thermoregulation is a cause. Familial HWE cases with more than one affected member have been noted in $7-15 \%$ of Indian patients. ${ }^{[3-7]} \mathrm{A}$ genetic locus in the $10^{\text {th }}$ chromosome had been identified (10q21, 3-q22,3). ${ }^{[11-13]}$

Interictal scalp EEG is technically difficult, but when performed it is usually normal. However $15-20 \%$ might show diffuse abnormalities. Lateralized or localized spike discharges in the anterior temporal regions have been reported in a few cases.

HWE in humans was managed in two ways previously: (a) Using lukewarm water for a head bath or sponging with hot towels, ${ }^{[3,4]}$ and (b) use of conventional AEDs such as PHT or carbamazepine (CBZ). The use of PHT or CBZ is generally indicated in children who have spontaneous seizures in addition to seizures triggered by 
hot water. Satishchandra et al. ${ }^{[4]}$ evolved a newer method of intermittent oral prophylaxis with benzodiazepines. They advocated the use of 5-10 mg of oral CLB 1.5-2 h before a head bath and not every day. This approach was used by us in the first case and was found to have satisfactory results. This approach minimizes the cost and side effects of these AEDs. Treatment with CLB can be considered in older children and in those with children with prolonged seizures following head bath with hot water, and in those who continue to have seizures even during regular baths with normal water temperature or nonreflex seizures It may be useful when the temperature of water cannot be reduced due to cultural and religious reasons.

Children with HWE generally have an excellent prognosis. HWE tend to subside with advancing age. There is no increased chance of developmental delay.

The above case descriptions were made to highlight the rarity of its occurrence and to emphasize that HWE could be controlled with CLB prior to bath and/or lifestyle modifications.

\section{Financial support and sponsorship}

Nil.

\section{Conflicts of interest}

There are no conflicts of interest.

\section{References}

1. Szymonowicz W, Meloff KL. Hot water epilepsy. Can J Neurol Sci 1978;5:247-51.

2. Allen IM. Observations on cases of reflex epilepsy. N Z Med J 1945;44:135-4.

3. Stensman R, Ursing B. Epilepsy precipitated by hot water immersion. Neurology 1971;99:224-6.

4. Satishchandra P, Shivaramakrishana A, Kaliaperumal VG, Schoenberg BS. Hot-water epilepsy: A variant of reflex epilepsy in southern India. Epilepsia 1988;29:52-6.

5. Incecik F, Hergüner MO, Elkay M, Altunbasak S. Hot water epilepsy - A report of three cases. Indian Pediatr 2004;41:731-3.

6. Argumosa A, Herranz JL, Barrasa J, Arteaga R. Reflex epilepsy from hot water: A new case and review of the literature. Rev Neurol 2002;35:349-53.

7. Mani KS, Mani AJ, Ramesh CK. Hot-water epilepsy - A peculiar type of reflex epilepsy: Clinical and EEG features in 108 cases. Trans Am Neurol Assoc 1974;99:224-6.

8. Subaramanayam HS. Hot water epilepsy. Neurol India 1972;20:S241-3.

9. Auvin S, Lamblin MD, Pandit F, Bastos M, Derambure P, Vallée L. Hot water epilepsy occurring at temperature below the core temperature. Brain Dev 2006;28:265-8.

10. Bebek N, Baykan B, Gürses C, Emir O, Gökyigit A. Self-induction behavior in patients with photosensitive and hot water epilepsy: A comparative study from a tertiary epilepsy center in Turkey. Epilepsy Behav 2006;9:317-26.

11. Fukuda M, Morimoto T, Nagao H, Kida K. Clinical study of epilepsy with severe febrile seizures and seizures induced by hot water bath. Brain Dev 1997;19:212-6.

12. Ullal GR, Satishchandra P, Shankar SK. Hyperthermic seizures: An animal model for hot-water epilepsy. Seizure 1996;5:221-8.

13. Ratnapriya R, Satishchandra P, Kumar SD, Gadre G, Reddy R, Anand A. A locus for autosomal dominant reflex epilepsy precipitated by hot water maps at chromosome 10q21.3-q22.3. Hum Genet 2009;125:541-9. 